\title{
The role of pore-size distribution function on the estimation of engineering properties of unsaturated soil
}

\author{
Q. Zhai ${ }^{\text {i),iii)*, H. Rahardjo }}{ }^{\text {ii) }}$, A. Satyanaga ${ }^{\text {ii) }}$, GL Dai ${ }^{\text {i) }}$ and XL Zhao ${ }^{\text {i) }}$
}

\author{
${ }^{i}$ Key Laboratory for RC and PRC Structures of the Ministry of Education, Southeast University, Nanjing, 210096 China \\ ii) School of Civil and Environmental Engineering, Nanyang Technological University, Block N1, Nanyang Ave., Singapore 639798, \\ Singapore.

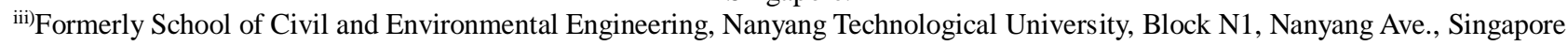 \\ 639798, Singapore. \\ * corresponding author. E-mail: $101012332 @$ seu.edu.cn
}

\begin{abstract}
Soil is a porous material which consists of a collection of soil particles with voids. The soil particles have different sizes with certain statistical distribution which are commonly described using grain-size distribution curve (GSD). The characteristic of GSD has significant effects on the engineering properties of the soil (especially for coarse-grained soil). On the other hand, the geometrical pore space in soil can be described by the pore-size distribution function (PSD). There are limited studies on the effect of PSD on the engineering properties of soil. For the soil with insignificant volume change, the soil-water characteristic curve (SWCC) is considered to be analogous to the PSD. In this paper, the soil skeleton is assumed to be rigid and the roles of PSD on the air/water flow in the unsaturated soil and on the unsaturated shear strength are explained. The proposed theories utilizing different PSDs are able to estimate the saturated hydraulic conductivities of different soil types. The proposed theories and equations are verified with experimental data from literatures.
\end{abstract}

Keywords: pore-size distribution function, soil-water characteristic curve, hydraulic conductivity, unsaturated shear strength

\section{INTRODUCTION}

The principles of unsaturated soil mechanics have been concerned and widely accepted by geotechnical engineers in recent decades. It is known that mechanical properties (such as permeability and shear strength) of unsaturated soils are different from those of saturated soils. Many studies have reported that the unsaturated soil properties could be estimated from the saturated soil properties through the soil-water characteristic curve (SWCC) which defines the relationship between the amount of water in soil and soil suction. As a result, the SWCC becomes a key to understand the mechanical properties of unsaturated soil. In this paper, the pore-size distribution function (PSD), which is considered to be analogous to SWCC, is adopted as the key information for the explanation of the mechanical properties of unsaturated soil.

Fredlund and Rahardjo (1993) and Fredlund et al. (2012) presented that SWCC was an effective interpretive model that used the elementary capillary model to provide an understanding of the distribution of water in the voids. In other words, that the capillary model can be used to illustrate the water retention in soil under a given soil suction. The "bundle of cylindrical capillaries" (BCC), as illustrated in Figure 1, is commonly used for the representation of pore space geometry (Millington and Quirk, 1961; Mualem, 1976, Tuller and Or 2004). As shown in Figure 1, the mount of water in soil can be simulated by the bundle of cylindrical capillary tubes. The radii of tubes represents the sizes of pores in soil and the water height in a tube represents the water amount existing in the corresponding pores in soil.

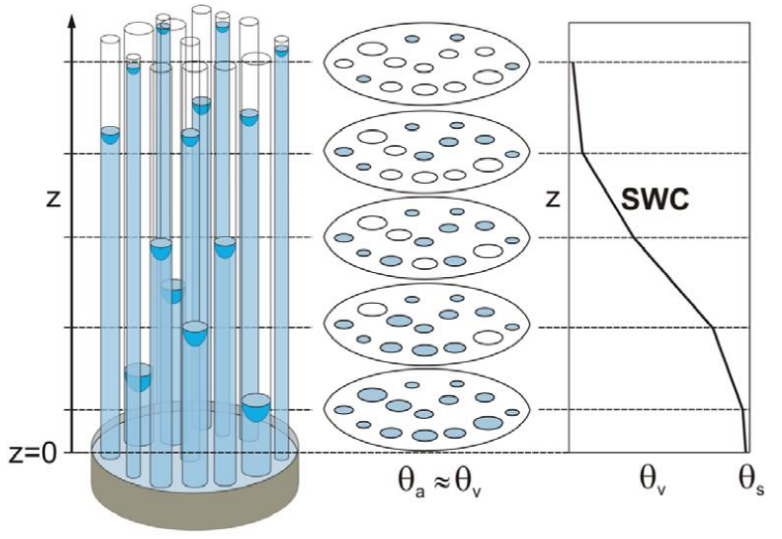

Figure 1. Illustration of BCC model (from Tuller and Or 2004), where $z$ represents capillary rising height, SWC represents soil water retention curve, $\theta_{s}$, 
represents saturated volumetric water content.

It is worthy to noted, that the capillary law which correlates the SWCC and PSD is based on the assumption that soil structure is rigid. In other word, SWCC can be considered as the integration of the PSD if there is no soil volume change. On the other hand, constitutive model, a mathematical equation defines the relationship between the soil properties and stress variables, is commonly used by geotechnical engineers. As a result, SWCC is commonly expressed using the SWCC best-fit equation which is a mathematical equation. There are different SWCC best fit equations or models have been proposed, such as Gardner 1958; Brooks and Corey 1964; van Genuchten 1980; Fredlund and Xing 1994; and Kosugi 1994. There are also many other best-fit equations and not listed all in this paper. Among these equations, Fredlund and Xing (1994) was considered as the first who proposed the SWCC best-fit equation by adopting the concept of pore-size distribution. By best-fitting different equations with the experimental data for different types of soil, Leong and Rahardjo (1997) concluded that Fredlund and Xing (1994)'s equation performed best in best-fitting the SWCC data for a wide range of soil over the entire range of matric suction. Zapata (1999) also recommended that van Genuchten's (1980) equation could perform well for best fitting fine-grained soils. However, due to space limitation, only Fredlund and Xing (1994)'s equation, as illustrated in Equation (1), is selected for the description of SWCC in this study.

$$
S=1-\frac{\ln \left(1+\frac{\psi}{C_{r}}\right)}{\ln \left(1+\frac{10^{6}}{C_{r}}\right)} \frac{1}{\left\{\ln \left[e+\left(\frac{\psi}{a}\right)^{n}\right]\right\}^{m}}
$$

where,

$C_{r}=$ input value, which can be a roughly estimated value for residual suction, $C_{r}=1500 \mathrm{kPa}$ for most cases as suggested by Fredlund and Xing (1994) and Zhai and Rahardjo (2012a, 2012b), $\psi=$ matric suction, e = Euler's number and $a, n$ and $m$ are fitting parameters.

Lambe (1955) indicated that the coefficient of permeability of soil was dependent on soil structure, text composition, porosity and degree of saturation. Tuli and Hopmans (2004) found that relationship between hydraulic or air conductivity and degree of saturation can be mainly affected by the pore geometry and size distribution of soil. Tuli et al. (2005) presented that water flow in soil was mainly governed by geometrical pore-space characteristics, which can be represented by the pore-size distribution function. Vogel (1997) and Wildenschild et al.(2005) showed that the microscopic studies of water flow in soil were driven by the lack of knowledge concerning the control of water flow by pore geometry. The statistical methods provide tools to quantify the water flow by using microscopic studies. Childs and Collis-George (1950) derived an equation for the estimation of the coefficient of permeability of soil from SWCC by adopting the statistical method and the concept of the pore-size distribution function. Mualem (1976) further developed the model from Childs and Collis-George (1950) by assuming that the capillary tubes to have certain length and proposed a pore tortuosity-connectivity parameter to improve the estimation of coefficient of permeability from SWCC. However, Mualem (1976) also indicated that the tortuosity-connectivity parameter could only be estimated empirically because there was no procedure available to determine this parameter. On the other hand, Zhai et al. (2018a) recommended that the estimation of unsaturated hydraulic conductivity from SWCC should consider the effect of soil volume change (change in the pore-size distribution function) rather than adopting an empirical parameter. Therefore, the empirical parameter of tortuosity-connectivity is not adopted in this paper. As there is no empirical parameter adopted, the relative coefficient of permeability of can be estimated from SWCC directly, vice versa. Therefore, the measured data of relative permeability function should also contain information about PSD. Zhai et al. (2017a, b, c, 2018b, c) presented the procedure of estimation of permeability function from measured SWCC and pore-size distribution function from the measured permeability data.

The object of this paper is to explain the role of the PSD on the engineering properties of soil such as SWCC and permeability function. Due to space constraint, the role of PSD on the results of unsaturated shear strength is not presented in this paper. Microscopic studies on the pores inside the soil (i.e., to check the possibility of water flow through the pores under different scenarios) were carried out so as to understand the principle of water flow in unsaturated soil. Mathematical equations, which are proposed by authors, are also introduced to estimate the engineering properties of soil by using the concept of pore-size distribution function.

\section{CAPILLARY AND VALVE MODEL FOR SIMULATION OF WATER FLOW IN UNSATURATED SOIL}

The limitations of conventional capillary model for description of water flow in soil are discussed. Subsequently, an improved capillary model for description of the pores in soil and water flow in soil is introduced by improving these limitations as mentioned. In the improved capillary model, the SWCC and pore-size distribution function are correlated by using the capillary law. Consequently, a "valve model" is introduced for the explanation of the principle of water 
flow in an unsaturated soil. By using this "valve model", the mathematical equation which can be used to estimate the permeability function of soil from measured SWCC data, and pore-size distribution function from measured permeability data is proposed.

\subsection{Conventional Capillary model}

Millington and Quirk (1961) and Mualem (1976) presented that the conventional capillary model was proposed based on the model of "bundle of cylindrical capillaries" (BCC), as illustrated in Figure 1. The BCC representation postulates that a portion of the interconnected cylindrical pores is completely liquid-filled at a given matric potential whereas larger pores are completely empty. As pointed out by Fredlund and Rahardjo (1993), Fredlund et al. (2012), Zhai et al. (2017c, 2018a), this BCC model introduced serious limitations in its general application to unsaturated soil mechanics.

In general, the limitations of conventional capillary models were summarized by Zhai et al. (2018b) as follows:

1. There is only a single tube for a particular pore size, which cannot represent the pore-size density for different pore sizes.

2. The water height in the tube is based on the capillary height and the total water amount in all these tubes may not be consistent with the water amount in soil with changes in matric suction.

3. The water drainage through a tube is piston-like, either fully filled or fully empty, which cannot represent actual water movement in an irregular pore.

4. The tubes are not connected to each other. As a result, this model cannot be used to explain the water flow in unsaturated soil.

5. As the tubes are not connected to each other, no "ink-bottle" effect can be created and this makes the model incapable of explaining the wetting process in the soil.

\subsection{Improved capillary model}

In order to overcome the limitations of the conventional capillary model as mentioned above, a new capillary model is proposed. At first an irregular pore is simplified into a series of circular pores with different sizes as illustrated in Figure 2. Secondly, on the cross-sectional area, there are numbers of circular pores with different radii, which are converted from different irregular pores, as illustrated in Figure 3(b). The number of circular pores with radius of $r$ is dependent on the pore-size density, $f(r)$, rather than on a single pore. In this case, the soil element illustrated in Figure 3(a) can be simplified as Figure 3(b).

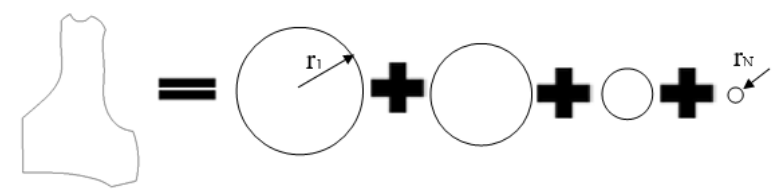

Figure 2. Simplification of an irregular pore into a series of circular pores.

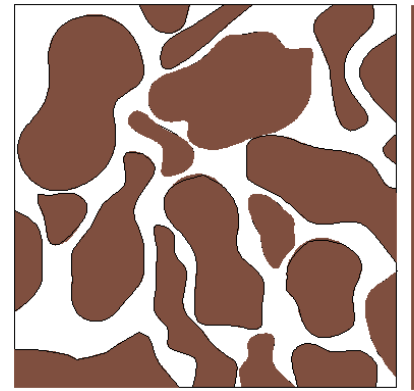

(a) irregular pores

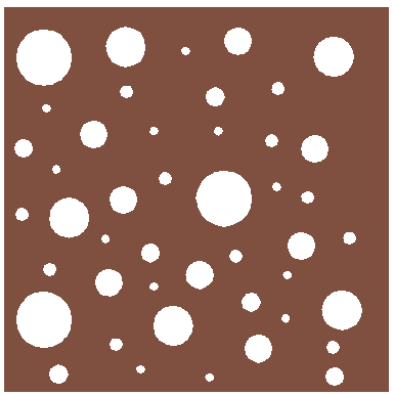

(b) simplified circular
Figure 3. Simplification of pores in soil element.

The porosity of soil can be defined by the total volume of these cylindrical tubes (or capillary tubes) $\sum \mathrm{V}_{\text {tube. }}$ As the width of soil element is defined as 1 , the porosity of soil can also be defined as the area of circular pores on the cross-sectional area, $\sum A_{\text {pore }}$, as follows:

$$
\sum A_{\text {pore }}=\sum_{i=1}^{N} n_{i} \pi r_{i}^{2}
$$

where, $\sum A_{\text {pore }}=$ total area of circular pores on the cross-sectional area, $n_{i}=$ total numbers of the pores with radius of $r_{i}, r_{l}$ is the maximum radius of a pore, $r_{N}$ is the minimum radius of a pore.

The pore-size distribution function defines the ratio of the volume of pores with certain radius of $r_{i}$ to the total volume of pores, and that ratio is commonly defined as the pore-size density $\mathrm{f}\left(r_{i}\right)$. Therefore, the pore-size density of pores with radius of $r_{i}, \mathrm{f}\left(r_{i}\right)$, can be calculated as follows:

$$
f\left(r_{i}\right)=\frac{n_{i} \pi r_{i}^{2}}{\sum_{i=1}^{N} n_{i} \pi r_{i}^{2}}
$$

This improved model can help to define the pore-size distribution function more clearly than the conventional capillary model. In addition, the volumes of pores in the element are consistent with the definition of porosity. As soil elements can be connected to each other, the cylindrical tubes can be assumed to be connected to each other. With random connectivity, the "ink-bottle" effect can be simulated. The detail of calculation of the "ink-bottle" effect can be found from Zhai et al. (2017c). 


\subsection{Relationship between SWCC and the pore-size distribution function}

If water fully fills the pores from $r_{j}$ to $r_{N}$, then the degree of saturation in the soil can be calculated from Equation (4) as follows:

$$
S\left(\psi_{j}\right)=\frac{\sum_{i=j}^{N} n_{i} \pi r_{i}^{2}}{\sum_{i=1}^{N} n_{i} \pi r_{i}^{2}}
$$

where, $r_{j}=$ the maximum radius of a pore which is filled with water.

It is observed that Equation (4) can be obtained by the summation of Equation (2) as follows:

$$
S\left(\psi_{j}\right)=\sum_{i=j}^{N} f\left(r_{i}\right)=\frac{\sum_{i=j}^{N} n_{i} \pi r_{i}^{2}}{\sum_{i=1}^{N} n_{i} \pi r_{i}^{2}}
$$

Therefore, as illustrated in Equation (5), SWCC in the form of degree of saturation can be obtained from the integration of the pore-size distribution function. Equation (5) gives the same conclusion from Fredlund and Xing (1994) namely that SWCC can be obtained by integrating the pore-size distribution function. It should be noted that Equation (5) was obtained based on the assumption that there is no soil volume change with changes in matric suction.

Therefore, the pore-size distribution function, $f(\psi)$, can be obtained by differentiation of the best fit equations, which are expressed using the fitting parameters $a, n$ and $\mathrm{m}$, as follows:

$$
f(\psi)=\frac{d S}{d \log (\psi)}=\psi \ln (10)\left[\begin{array}{l}
\frac{1}{\ln \left(1+\frac{10^{6}}{C_{r}}\right)\left(1+\frac{\psi}{C_{r}}\right) C_{r}\left\{\ln \left[e+\left(\frac{\psi}{a}\right)^{n}\right]\right\}^{m}}+ \\
\frac{m n\left(\frac{\psi}{a}\right)^{n-1}\left[1-\frac{\ln \left(1+\frac{\psi}{C_{r}}\right)}{\left.\ln \left(1+\frac{10^{6}}{C_{r}}\right)\right]}\right.}{a\left[e+\left(\frac{\psi}{a}\right)^{n}\right]\left[\ln \left[e+\left(\frac{\psi}{a}\right)^{n}\right]\right\}^{m+1}}
\end{array}\right]
$$

where, $a, n$ and $m$ are the fitting parameters in Fredlund and Xing (1994)'s equation.

\subsection{Valve model for unsaturated permeability of soil}

The water valve, as illustrated in Figure 4 (a) is commonly used in houses; it has the internal structural design illustrated in Figure 4 (b). Its working mechanism is explained and illustrated in Figure 5.

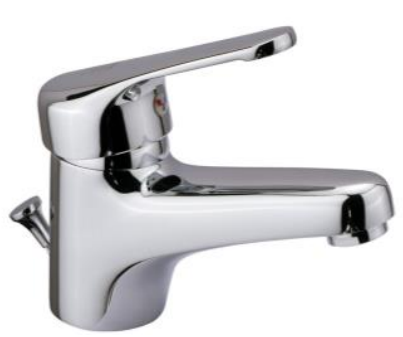

(a)Illustration of water valve. structure of water valve

Figure 4. Illustration of water valve.
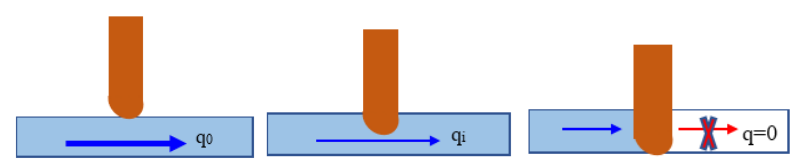

(a)The valve is open (b) The valve is half open (c) The valve is closed

Figure 5. Illustration of working mechanism of a water valve.

When the valve is fully opened, the cross-sectional area is completely open for water flow, as illustrated in Figure 5 (a), the effective area that allows water to flow is $A_{0}$ and the water flow rate reaches its maximum value, $q_{0}$. When the valve is half opened, the effective cross-sectional area is reduced to $A_{i}$ which results in a smaller flow rate, $q_{i}$. When the valve is closed, the effective cross-sectional area becomes zero and the flow rate also reduces to zero. The flow rate $q_{i}$ can be calculated from the ratio between $A_{i}$ and $A_{0}$ as illustrated in Equation (9). The reduction in the cross-sectional area can be calculated from the pore-size distribution function using the statistical method.

$\frac{q_{i}}{q_{0}}=\frac{A_{i}}{A_{0}}$

The results of experimental work from Reinson et al. (2005) showed that water could flow only through the water phase and could not flow through the air phase. Assume two soil elements connect each other on section A-A, the water flow through the section is dependent on the moisture condition of the two pores as illustrated in Figure 6. If both pores are wet (as illustrated in Figure 6a), then water can flow across the section. On the other hand, if one pore is dry (as illustrated in Figure 6b), then water is blocked by air and cannot flow across the section. The probability of the connection of two pores is dependent on the pore-size density of the pores. 


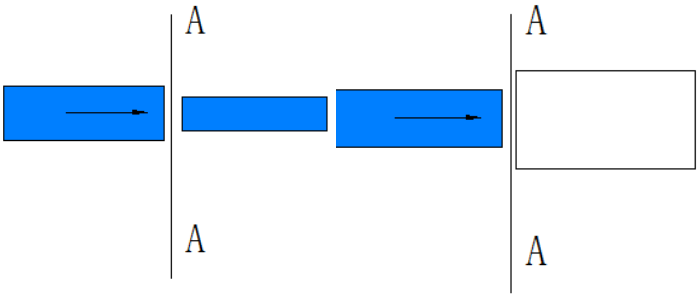

(a) Two pores are wet, (b) Two pores are dry

Figure 6. Illustration of water flow cross the section.

In this case, if the effective area that allows water flow through the section can be calculated, then the relative coefficient of permeability can be calculated. By studying the effective area for each individual pore (from $r_{m}$ to $r_{N}$, where $r_{m}$ is the maximum radius of wet pore corresponding to matric suction of $\psi_{m}$ ), the total effective area on the cross-sectional area that allows water flow can be calculated as illustrated in Figure 7.

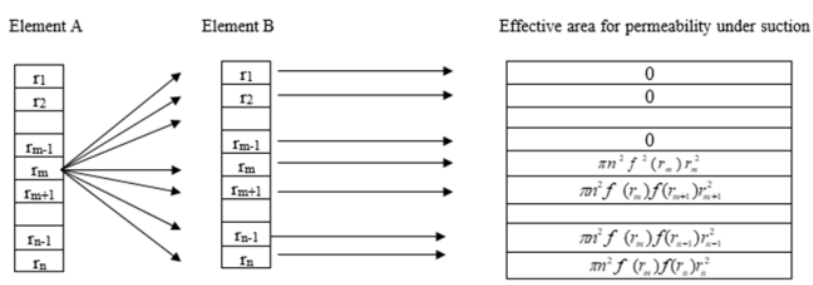

Figure 7. Illustration of effective area for each pore

The summation of the effective areas under suction of $\psi_{m}$ can be divided by the total effective area under the fully saturated condition to determine the relative coefficient of permeability as shown in Equation (8).

$$
k_{r}=\frac{\left\{\begin{array}{l}
\left(S\left(\psi_{m}\right)-S\left(\psi_{m+1}\right)\right)^{2} \psi_{m}^{-2}+ \\
\sum_{i=m+1}^{N}\left[\left(S\left(\psi_{m}\right)-S\left(\psi_{i}\right)\right)^{2}-\left(S\left(\psi_{m}\right)-S\left(\psi_{i-1}\right)\right)^{2}\right] \psi_{i}^{-2}
\end{array}\right\}}{\left.\sum_{i=1}^{N}\left[1-S\left(\psi_{i}\right)\right]^{2}-\left[1-S\left(\psi_{i-1}\right)\right]^{2}\right] \psi_{i}^{-2}}
$$

where, $k_{r}=$ relative coefficient of permeability, $\psi_{m}=$ matric suction in the soil and $S\left(\psi_{m}\right)=$ the degree of saturation corresponding to matric suction of $\psi_{\mathrm{m}}$.

Substituting Fredlund and Xing (1994)'s equation into Equation (8) the relative coefficient of permeability can be obtained using fitting parameters $(a, n$ and $m)$ as follows:

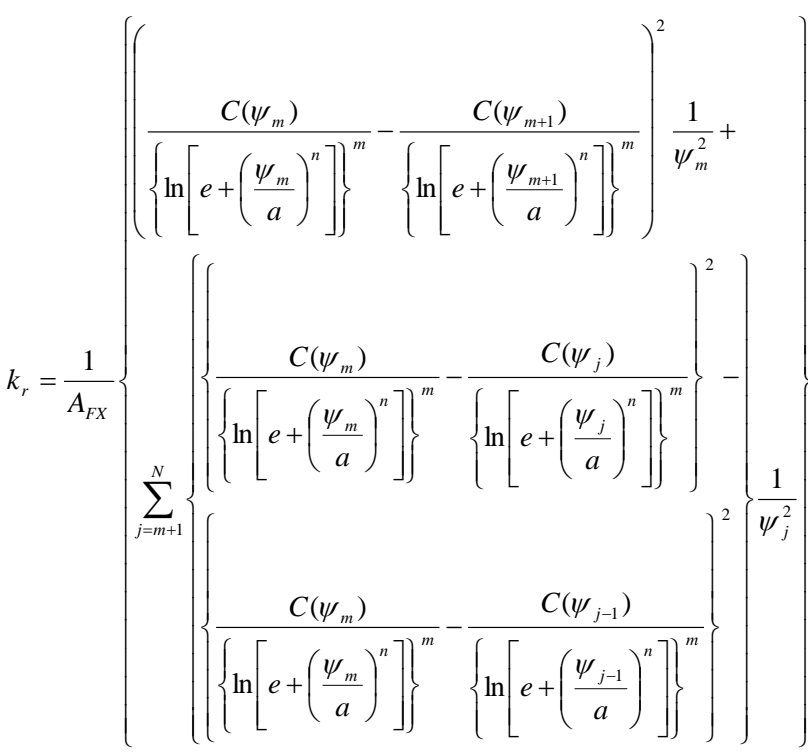

where,

$$
A_{F X}=\sum_{i=1}^{N}\left\{\left\{1-\frac{C\left(\psi_{i}\right)}{\left\{\ln \left[e+\left(\frac{\psi_{i}}{a}\right)^{n}\right]\right\}^{m}}\right\}^{2}-\left\{1-\frac{C\left(\psi_{i-1}\right)}{\left\{\ln \left[e+\left(\frac{\psi_{i-1}}{a}\right)^{n}\right]\right\}^{m}}\right\}\left\{\frac{1}{\psi_{i}^{2}}\right.\right.
$$

$a, n$ and $m$ are fitting parameters in Fredlund and Xing (1994)'s equation

It is observed from Equations (1), (6) and (9) that SWCC, pore-size distribution function, $\mathrm{f}(r)$, and relative coefficient of permeability, $k_{r}$, can be expressed by the same set of fitting parameters. (i.e., $a, n$ and $m$ in Fredlund and Xing (1994)'s equation). In this case, if any of these properties: SWCC, $\mathrm{f}(r)$, or $k_{r}$, is known, the other two properties can be calculated accordingly. The proposed method in this paper is also applicable to the van Genuchten (1980) equation and the detail of derivation can be found from Zhai et al. (2018a, b).

\section{EXPERIMENTAL PROGRAMS FOR VERIFICATION}

In order to verify the capability of Equations (11) and (13), one specimen of a compacted mixture of sand and kaolin K50S50 (50\% sand with 50\% kaolin) was prepared for both an unsaturated permeability test and SWCC measurement. The unsaturated permeability tests were carried out using the triaxial permeameter. The unsaturated triaxial permeameters were set up following the modifications recommended by Goh (2012), Rahimi and Rahardjo (2016), Goh et al. (2015) and Priono (2016). The schematic diagram of the setting up of the unsaturated triaxial permeameter is illustrated in Figure 8. 


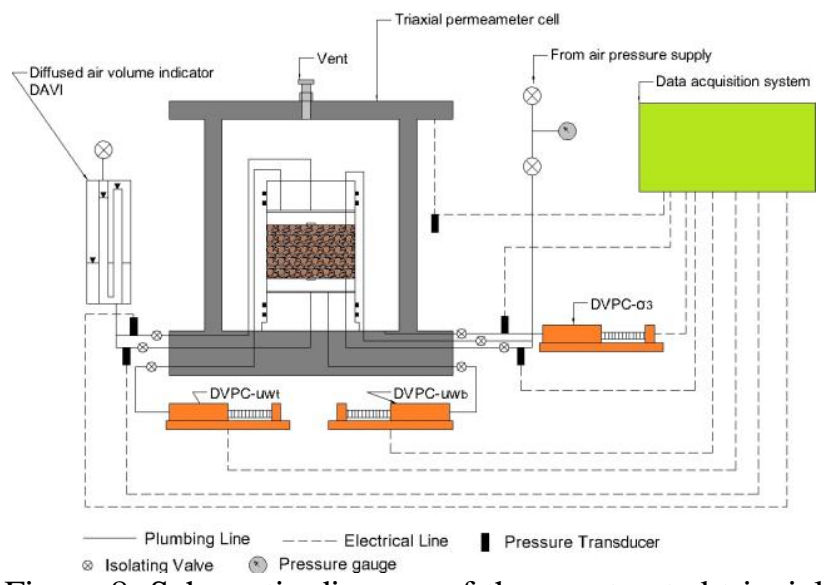

Figure 8. Schematic diagram of the unsaturated triaxial permeameter setup

The unsaturated permeability test was stopped when the equilibrium condition was achieved. The equilibrium condition, i.e. a condition when there is no change in water volume, is usually determined by graphical method, similar to the determination of equilibrium time in the SWCC test. After the permeability test was completed at each suction stage, the equilibrium state was reached for the conventional SWCC measurement. Following this procedure, the unsaturated permeability and SWCC could be measured simultaneously.

Index properties tests were conducted on compacted soils, a soil mixer with L2-grade kaolin and 20-30 Ottawa sand, and the index properties of this compacted soil (K50S50) are summarized in Table 1.

Table 1: Index properties of soils used in this study.

\begin{tabular}{|l|c|}
\hline Index properties & K50S50 \\
\hline Dry Density, $\rho_{\mathrm{d}}\left(\mathrm{Mg} / \mathrm{m}^{3}\right)$ & 1.75 \\
\hline Water Content, $\mathrm{w}(\%)$ & 12.1 \\
\hline Void Ratio, $\mathrm{e}$ & 0.48 \\
\hline Liquid Limit, LL (\%) & 46.7 \\
\hline Plastic Limit, PL (\%) & 27.4 \\
\hline Plasticity Index, PI (\%) & 19.3 \\
\hline Specific Gravity, $\mathrm{G}_{\mathrm{s}}$ & 2.59 \\
\hline GSD - Sand $(\%)$ & 50.0 \\
\hline GSD - Silt $(\%)$ & 37.5 \\
\hline GSD - Clay $(\%)$ & 12.5 \\
\hline $\begin{array}{l}\text { Unified Soil Classification System } \\
\text { (USCS) }\end{array}$ & $\mathrm{SM}-\mathrm{ML}$ \\
\hline Saturated permeability $\mathrm{k}_{\mathrm{s}}(\mathrm{m} / \mathrm{s})$ & $1.12 \times 10^{-8}$ \\
\hline
\end{tabular}

In addition to the experimental measurements carried out in this study, another two sets of data including touch silt loam from Brooks and Corey (1964), superstition sand from Richards (1952) were collected from different reports. As no index properties of these soils were reported in the literature, only the experimental data of the relative coefficient of permeability and SWCC for these soils are illustrated in Figure 9.

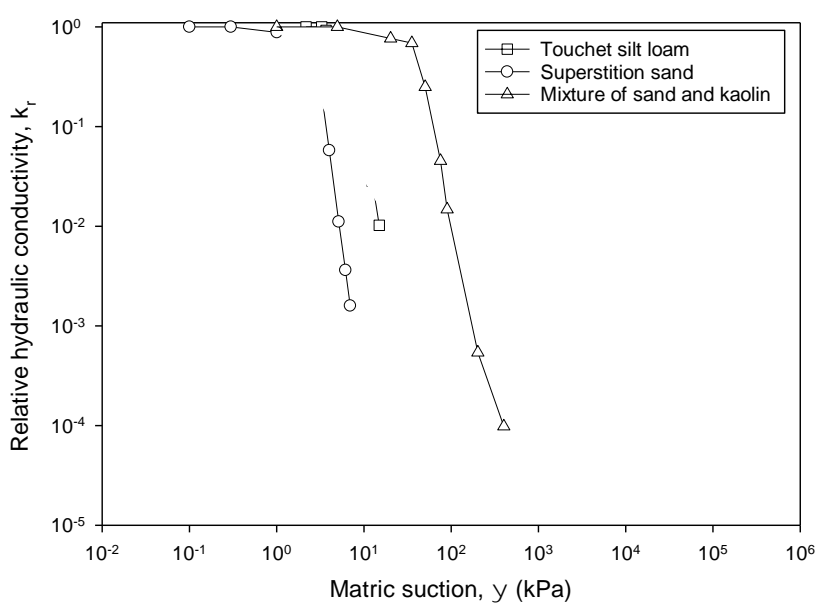

(a) Measured relative hydraulic conductivity for six types of soils

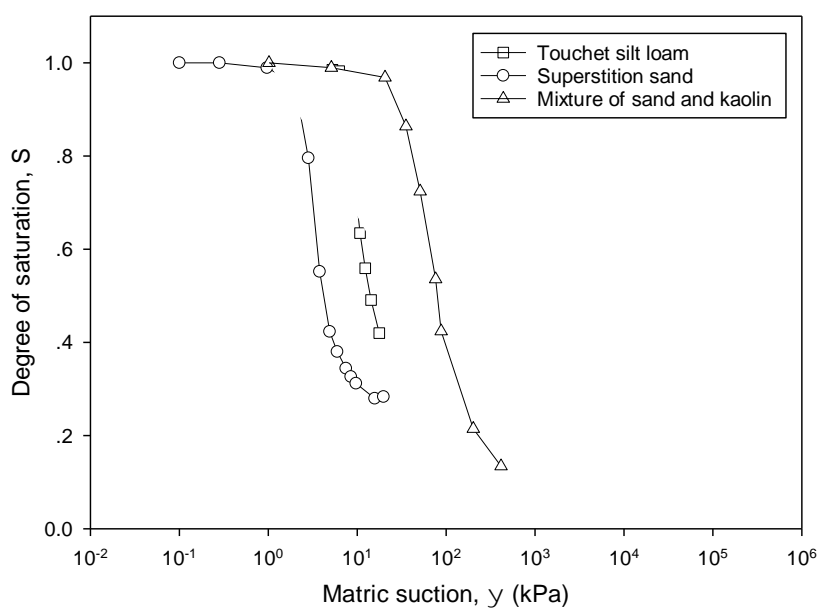

(b) Measured SWCC for six types of soils

Figure 9. Experimental data of relative hydraulic conductivity and SWCC of six types of soils.

Equation (9) was used to best fit the measured data of relative coefficients of permeability using curve fitting technique. After obtaining the fitting parameters in the Fredlund and Xing (1994) equation (i.e., $a, n$ and $m$ ) from the regression procedure, these fitting parameters were then used to calculate SWCC. Consequently, the calculated SWCCs were compared with the measured SWCCs for these three types of soil.

\section{RESULTS AND DISCUSSIONS}

The fitting parameters such as $a, n$ and $m$ in the Fredlund and Xing (1994) equation obtained from the best fit procedure (by minimizing $\Sigma\left(\log \left(k_{r i}\right)-\log \left(k_{r i}{ }_{r i}\right)\right)^{2}$, where $k_{r i}$ is the measured relative hydraulic conductivity and $k_{r i}^{\prime}$ is the estimated relative hydraulic conductivity from Equation (9) are presented in Tables 2. The best fitting results for the relative hydraulic conductivity for these soils are illustrated in Figure 10. Subsequently, the determined fitting parameters in Tables 2 were used to estimate the SWCC for these 
soils and the estimation results are illustrated in Figure 11. The coefficients of goodness between the estimated results and the experimental results of SWCC for these soils are presented in Table 3.

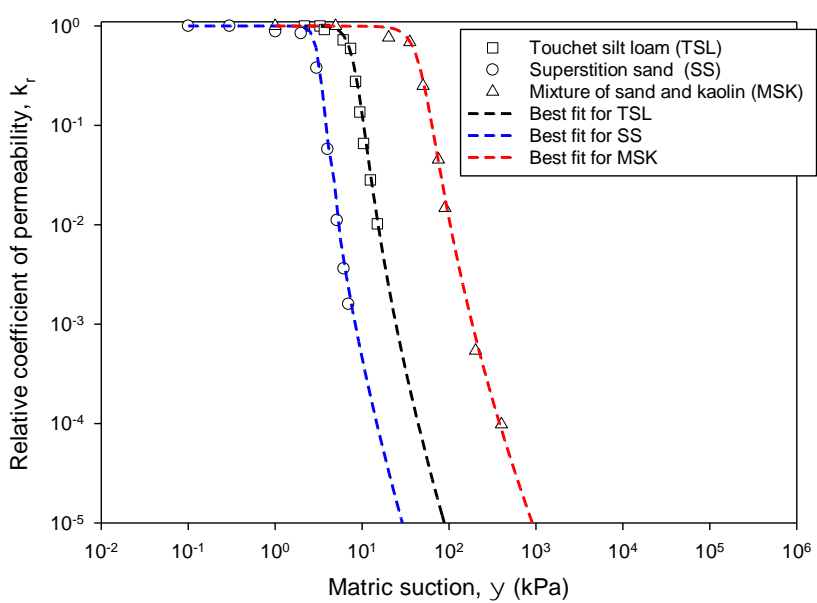

Figure 10. Best fitting results for these soils using Equations (9)

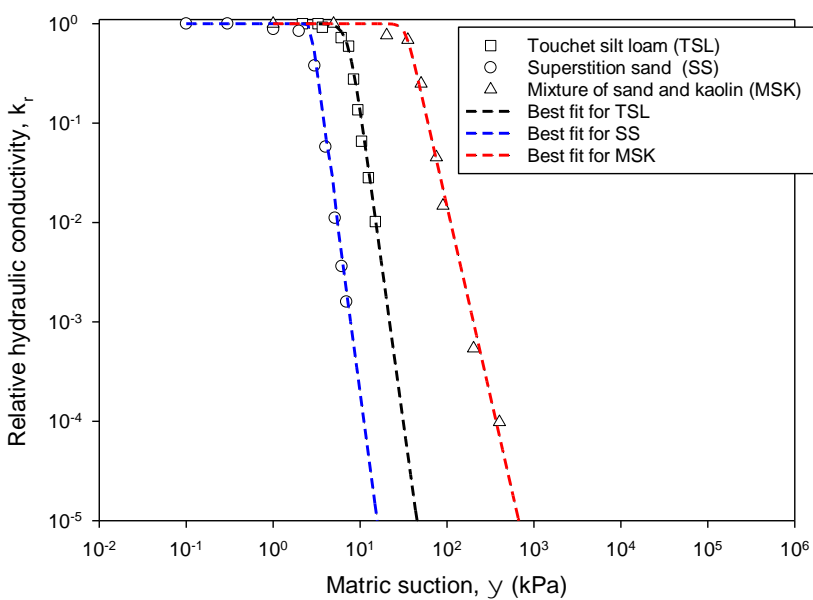

Figure 11. Estimated SWCC using fitting parameters from Figure 10.

Table 2. The fitting parameters obtained by best fitting equations (9) on experimental data of relative coefficient of permeability.

\begin{tabular}{|c|c|c|c|c|}
\hline \multirow{5}{*}{$\begin{array}{l}\text { Soils } \\
\text { Touch silt loam } \\
\text { Silty sand } \\
\text { Mixture of sand } \\
\text { and kaolin }\end{array}$} & \multicolumn{4}{|c|}{$\begin{array}{l}\text { Fredlund and Xing (1994)'s } \\
\text { equation }\end{array}$} \\
\hline & $\mathrm{a}(\mathrm{kPa})$ & $\mathrm{n}$ & $\mathrm{m}$ & $\mathrm{R} 2$ \\
\hline & 7.76 & 6.38 & 0.76 & $98.80 \%$ \\
\hline & 3.03 & 10.19 & 0.67 & $99.78 \%$ \\
\hline & 43.74 & 4.95 & 0.59 & $99.77 \%$ \\
\hline
\end{tabular}

Table 3. The coefficient of goodness, $\mathrm{R}^{2}$, for the estimation of SWCC using Equation (9)

\begin{tabular}{ll}
\hline Soils & Using Equation (9) \\
Touch silt loam & $95.22 \%$ \\
Silty sand & $95.70 \%$ \\
$\begin{array}{l}\text { Mixture of sand } \\
\text { and kaolin }\end{array}$ & $99.02 \%$ \\
\hline
\end{tabular}

The results shown in Figure 10 and Table 2 indicated that Equation (9) performed well (high values of $\mathrm{R}^{2}$ ) as the best fit equations for the permeability function. The results illustrated in Figure 11 and Table 3 indicated that the estimation results of SWCC from the measured data of relative coefficient of permeability also agreed with the measured data of SWCC.

\section{CONCLUSIONS}

The conventional capillary model was improved and a "valve model" was proposed to explain the water flow in unsaturated soil. The relationships between SWCC, pore-size distribution function and permeability function could be well explained using the proposed models. It is observed that pore-size distribution function acts as a bridge to link SWCC and the permeability function. By best fitting the experimental data (including measured data in this study and published data collected from literature) with the proposed equations, the pore-size distribution function can be indirectly obtained from the measured permeability data. Therefore, in the situation that only experimental data of relative coefficient of permeability are available, pore-size distribution function, $\mathrm{f}(r)$, still can be indirectly obtained by using the equations proposed in this study.

\section{ACKNOWLEDGEMENT}

The first author would like to acknowledge the financial supports he received from the National Natural Science Foundation of China (No. 51878160), the National Key Research and development program of China (No. 2017YFC00703408) and the Fundamental Research Funds for the Central Universities (No. 2242018K41046).

\section{REFERENCES:}

1) Brooks, R.H., and Corey, A.T. (1964) "Hydraulic properties of porous media." Hydrology Paper, No. 3 Colorado State Univ., Fort Collins Colo.

2) Childs, E.C. and Collis-George, N. (1950). "The Permeability of Porous Materials". Proceedings of the Royal Society of London. Series A, Mathematical and Physical Sciences, 201(1066):392-405.

3) Fredlund, D.G. and Xing, A. (1994) "Equations for the soil-water characteristic curve." Canadian Geotechnical Journal, 31(3): 521-532.

4) Fredlund, D. G. and Rahardjo H. (1993) "Soil Mechanics for unsaturated soil", Wiley, New York.

5) Fredlund D.G. ,Rahardjo H. and Fredlund M.D. (2012) "Unsaturated Soil Mechanics in Engineering Practice." Wiley, New York

6) Gardner, W.R (1958) "Mathematics of isothermal water conduction in unsaturated soils. " Highway Research Board Special Rep. No. 40, International Symposium on physic-Chemical Phenomen in Soils, Washigton, D.C. 
78-87.

7) Goh, S.G. (2012) "Hysteresis effects on mechanical behavior of unsaturated soil" Ph.D thesis. Nanyang Technological University.

8) Goh, S.G., Rahardjo, H., Leong, E.C. (2015). "Modification of triaxial apparatus for permeability measurement of unsaturated soils". Soils and Foundations, 55(1):63-73.

9) Kosugi K (1994) "Three-parameter lognormal distribution model for soil water retention". Water Resources Research Vol 30 No. 4 Pages 891-901.

10) Lambe, T.W. (1955) "The permeability of compacted fine grained soils.” ASTM, Special Tech. Pub. NO. 163.

11) Leong, E.C. and Rahardjo H. (1997) "Review of soil-water characteristic curve equations." J. Geotech. Geoeniron. Eng 123(12), 1106-1117.

12) Milington, R.J., and J.P. Quirk, (1961) "Permeability of porous media," Nature, 183, 387-388.

13) Mualem, Y. (1976) "A new model for predicting the hydraulic conductivity of unsaturated porous media," Water Resour. Res., 12(3):513-522.

14) Priono (2016) "Anisotropy in hydraulic properties of unsaturated soils" Ph.D thesis. Nanyang Technological University.

15) Reinson J. R., Fredlund D. G. and Wilson G. W. (2005) "Unsaturated flow in coarse porous media." Canadian Geotechnical Journal, 42: 252-262.

16) Richards, L.A. (1952) "Water conducting and retaining properties of soils in relation to irrigation." In Proceedings of an International Symposium on Desert Research, Jerusalem. pp. 523-546

17) Tuller M. and Or D. (2004) "Retention of water in soil and soil-water characteristic curve." Encyclopedia of Soils in the Environment.

18) Tuli A, Hopmans J. W., Rolston D. E. and Moldrup P. (2005) "Comparison of air and water permeability between disturbed and undisturbed soils" Soil Sci Soc. Am. J. 69: 1361-1371.

19) Tuli, A., and J.W. Hopmans. (2004) "Effect of degree of fluid saturation on transport coefficients in disturbed soils." Eur. J. Soil Sci. 55: 147-164.

20) van Genuchten, M.T. (1980) "A close form equation predicting the hydraulic conductivity of unsaturated soil." Soil Sci. Soc Am. J 44, 892-898.

21) Vogel, H.J. (1997) "Morphological determination of pore connectivity as a function of pore size using serial sections". Eur. J. Soil Sci. 48: 365-377.

22) Wildenschild, D., J.W. Hopmans, M.L. Rivers, and A.J.R. Kent. (2005) "Quantitative analysis of flow processes in a sand using synchrotron $x$-ray microtomography." Vadose Zone J. 4:112-126.

23) Zapata, C. E. (1999). "Uncertainty in Soil-Water Characteristic Curve and Impacts on Unsaturated Shear Strength Predictions", Ph.D. Dissertation, Arizona State University, Tempe, United States.

24) Zhai Q, Rahardjo H. (2012a) "Determination of soil-water characteristic curve variables." ComputGeotech 2012;42:37-43.

25) Zhai Q, Rahardjo H. (2012b) " Reply to the discussion by Bellia et al. on "Determination of soil-water characteristic curve variables" by Zhai Q, Rahardjo $\mathrm{H}$. ComputGeotech 2012;42:37-43 " ComputGeotech Volume 45, Pages $151-152$

26) Zhai Q, and Rahardjo H. (2015) "Estimation of permeability function from Soil-Water Characteristic Curve" Engineering Geology 199 (2015) 148-156.

27) Zhai Q., Rahardjo H. and Satyanaga, A.( 2017a) "Effect of bimodal soil-water characteristic curve on the estimation of permeability function " Engineering Geology 230: 142-151

28) Zhai Q., Rahardjo H. and Satyanaga, A. (2017b) "Effects of residual suction and residual water content on the estimation of permeability" Geoderma 303: 165-177

29) Zhai, Q., H. Rahardjo., and A. Satyanaga (2017c) "Uncertainty in the estimation of hysteresis of Soil-water Characteristic Curve", Environmental Geotechnics, Doi:/10.1680/ jenge.17.00008.

30) Zhai Q., Rahardjo H. and Satyanaga, A. (2018a) "Estimation of air permeability from soil-water characteristic curve" Canadian Geotechnical Journal (in press)

31) Zhai Q., Rahardjo H., Satyanaga, A. and G.L Dai(2018b) "Role of the pore-size distribution function on water flow in unsaturated soil" Journal of Zhejiang University-SCIENCE A (Applied Physics \& Engineering) (in press)

32) Zhai Q, Rahardjo H, Satyanaga A, (2018c) "A pore-size distribution function based method for estimation of hydraulic properties of sandy soils." Engineering Geology 246 (2018) 288-292 